\title{
A cytotoxic haemolysin from Treponema hyodysenteriae- a probable virulence determinant in swine dysentery
}

\author{
R. J. LYSONS, K. A. KENT,* A. P. BLAND, R. SELLWOOD, W. F. ROBINSON, \\ and A. J. FROST‡
}

AFRC Institute for Animal Health, Compton Laboratory, Compton, Newbury, Berkshire RG16 ONN, +School of Veterinary Studies, Murdoch University, Murdoch, Western Australia 6150, and $\ddagger$ Faculty of Veterinary Science, University of Queensland, St Lucia, Brisbane, Australia 4067

\begin{abstract}
Summary. The haemolysin from a virulent strain of Treponema hyodysenteriae was extracted and injected into ligated loops of the ileum and colon of germ-free pigs. It caused severe epithelial damage, especially to the differentiated cells at the tips of the villi in the ileum and the cells in the intercrypt zones of the colon; goblet cells were less affected. The changes in the colon were similar to those seen in natural cases of swine dysentery. The ligated loop offers a means of investigating pathogenic mechanisms and the mode of action of the toxin. This study demonstrated that the haemolysin was a potent cytotoxin for pig enterocytes, and a probable virulence determinant in swine dysentery.
\end{abstract}

\section{Introduction}

Swine dysentery is a severe disease of pigs caused by Treponema hyodysenteriae and characterised by mucohaemorrhagic diarrhoea associated with lesions in the large intestine. ${ }^{1}$ These are confined largely to the epithelial surface and, though $T$. hyodysenteriae may be seen within epithelial cells, invasion is not considered to be an essential component of pathogenesis. ${ }^{2}$ Two toxins that may cause epithelial damage have been described: a lipopolysaccharide (LPS) endotoxin and a haemolysin. The LPS may have a direct effect on the colonic enterocytes; ${ }^{3}$ and the haemolysin of a virulent strain was shown to be cytotoxic in vitro for a number of cell types. ${ }^{4}$

$\beta$-Haemolysis is a cultural characteristic that distinguishes $T$. hyodysenteriae from non-pathogenic, intestinal spirochaetes. The haemolysin, which has been partially purified, ${ }^{5}$ is similar in many respects to streptolysin $\mathrm{S},{ }^{6}$ e.g., a carrier molecule is required for in-vitro demonstration of haemolytic activity from metabolically active organisms. ${ }^{7}$

In this paper we report that the haemolysin is cytotoxic in ligated loops of the ileum and colon of germ-free pigs and suggest that it is a virulence determinant in swine dysentery.

\section{Materials and methods}

\section{Bacteria}

T. hyodysenteriae strain P18A was isolated from a

Received 6 March 1990: accepted 19 July 1990.

* Present address: National Institute for Biological Standards and Control, Blanche Lane, South Mimms, Potters Bar, Hertfordshire EN6 3QG. pig with swine dysentery induced by cultures of strain A1, the isolate used by Taylor and Alexander. ${ }^{8}$

\section{Haemolysin}

Haemolysin from $T$. hyodysenteriae was prepared as described by Kent $e t$ al. ${ }^{5}$ The carrier system used to enhance production in vitro was $0.05 \%$ RNA-core Type IIC from Torula yeast (Sigma). The haemolysin was titrated for haemolytic activity against sheep erythrocytes. ${ }^{7}$ One haemolytic unit (HU) is defined as the amount of haemolysin required to lyse $50 \%$ of the erythrocytes in a $1 \%$ suspension in phosphate-buffered saline. The haemolysin preparations were concentrated (no more than 20 -fold) and desalted at $4{ }^{\circ} \mathrm{C}$ with a YM5 Diaflow ultrafilter (Amicon), dispensed in ampoules of $100000 \mathrm{HU} / \mathrm{ml}$ and stored at $-20^{\circ} \mathrm{C}$. The haemolytic titre was confirmed at the time of use.

\section{Pigs and experimental procedure}

Germ-free pigs were used so that interactions with potential pathogens or other organisms could be excluded. Germ-free, Large White/Landrace pigs were derived by hysterotomy ${ }^{9}$ and reared in an isolator from birth until used. Pigs 1-7 were 35-37 days old and pigs 8 and 9 were 49 days old. Rectal swabs were cultured on blood agar plates anaerobically and aerobically at weekly intervals and at the time of the experiment to confirm the germ-free status of the pigs. Pig 2 was found to have a microbial contaminant of the gut and was, therefore, excluded from the experiments. The animals were fed a diet of evaporated milk supplemented with iron and copper until 4 days before gut ligation. In an attempt to minimise the amount of contents in the lower intestine, they were then fed a low residue diet (Vivonex; Norwich Eaton 
Ltd, Newcastle-upon-Tyne), designed for human use and containing all nutrients essential for man. Because of its cost and relative unpalatability for pigs, the Vivonex was mixed with a dextrose/electrolyte preparation (Lectade; Beecham Animal Health, Brentford, Middlesex). The animals were not fed on the day of experiment, except for pig 5 , which was accidentally fed $2 \mathrm{~h}$ before gut ligation.

\section{Surgical procedure}

Anaesthesia was induced and maintained with halothane. The intestine was exposed and ligated loops $1.5 \mathrm{~cm}$ long were prepared in the large intestine, ${ }^{10}$ near the sigmoid flexure of the coiled colon, and also in the ileum, at least $30 \mathrm{~cm}$ anterior to the ileo-caecal valve. The ileum was usually empty (except for pig 5). In a number of pigs the colon contained a considerable amount of viscous material, but the parts used were those with few or no contents. The volume of the haemolysin preparation injected was $0.7-1.0 \mathrm{ml}$, which filled but did not distend the loops. Animals were maintained under anaesthesia until the end of the experiment, when the ligated sections of gut were fixed in situ by injecting glutaraldehyde $(3 \% \mathrm{v} / \mathrm{v}$ in $0.1 \mathrm{M}$ phosphate buffer, $\mathrm{pH} \mathrm{7.3)}$ into the lumen. The pigs were then killed with an intravenous injection of pentabarbitone and the gut loops were excised, placed in fresh glutaraldehyde fixative and their ligated ends were removed.

\section{Microscopy}

After immersion in fixative for $2 \mathrm{~h}$, small pieces of tissue were placed in fresh fixative before processing for transmission electronmicroscopy (TEM). The tissues were washed in $0 \cdot 1 \mathrm{M}$ phosphate buffer, $\mathrm{pH} 7 \cdot 3$, post-fixed in Millonig's osmium tetroxide $1 \%$, washed in copious amounts of distilled water and further fixed en bloc with aqueous uranyl acetate $1 \%$. The tissue was then dehydrated through graded alcohols before being treated with epoxy propane and embedded in Araldite. Sections ( $1 \mu \mathrm{m}$ thick) were cut from the Araldite blocks and stained with toluidine blue $0.1 \%$ for examination by light microscopy (LM). Areas were selected for examination by TEM. Ultrathin sections were cut, stained with lead hydroxide and examined in a transmission electronmicroscope (Philips EM300) at an accelerating voltage of $80 \mathrm{kV}$. Pieces of ileum for scanning electronmicroscopy (SEM) were washed in $0 \cdot 1 \mathrm{M}$ phosphate buffer, $\mathrm{pH} 7 \cdot 3$, and post-fixed in Millonig's osmium tetroxide $1 \%$. They were further treated with thiocarbohydrazide and aqueous osmium tetroxide $1 \%$, ${ }^{11}$ dehydrated with acetone, critical point dried with liquid $\mathrm{CO}_{2}$ and coated with a thin layer of platinum. Pieces of colon were processed for SEM as described above, but the thiocarbohydrazide-osmium step was omitted. The tissue was examined in a scanning electronmicroscope (Hitachi S-520) at an accelerating voltage of $20 \mathrm{kV}$.

\section{Experimental design}

Pigs were prepared for experiment as they became available, the treatment for each being determined in part by the results of the previous experiments. The doses of haemolysin used and the duration of exposure are shown in the table. Seven control loops in the ileum of pigs 3-7 were inoculated with the following: phosphate-buffered saline; the RNA core at 2,10 and 20 times the concentration present in the haemolysinextraction solution (i.e., $0 \cdot 1,0.5$ and $1.0 \%$ ); haemolysin, $100000 \mathrm{HU} / \mathrm{ml}$, heat inactivated at $56^{\circ} \mathrm{C}$ for 60 min; whole culture of $T$. hyodysenteriae strain P18A; and culture supernate concentrated 10 times. Pigs 1,8 and 9 each had one control loop only, inoculated with $0.5 \%$ RNA solution. Control loops in the colon of the eight pigs were inoculated with $1 \%$ RNA solution. All control loops were exposed for $3 \mathrm{~h}$.

The tissue damage was assessed as severe, moderate, mild or nil by LM and SEM (table).

\section{Results}

No fluid accumulation occurred in any loop and there was no haemorrhage, reddening or other macroscopic abnormality. Microscopic lesions were present in some of the loops inoculated with haemolysin, but no changes were detected in any control loop.

\section{Effects on the ileum}

At a concentration of $100000 \mathrm{HU} / \mathrm{ml}$, the haemolysin produced extensive damage to the ileal epithelium. The effects, which affected mainly the enterocytes, are outlined in the table. The response varied between pigs, but the highest dose produced severe lesions in all animals except pig 5. SEM of the tissue from control loops revealed long finger-like villi (fig. 1a). However, after exposure for $3 \mathrm{~h}$ to haemolysin, the villi were almost obliterated, masses of exfoliated cells virtually obscuring the underlying surface (fig. 1b). Severely stunted villi were seen by LM, with an accumulation of goblet cells over the damaged area (fig. 1c). The remaining cells were cuboidal rather than columnar as in the control sections. Cells of the crypts were unaffected and the adjacent, lowest parts of the villi had also generally escaped damage. No denuded areas of mucosa were observed and there was no haemorrhage or accumulation of inflammatory cells.

Lower concentrations of haemolysin in the ileum produced less consistent damage, though exposure to $50000 \mathrm{HU} / \mathrm{ml}$ for $3 \mathrm{~h}$ produced effects that were often similar in severity to those produced by 100000 $\mathrm{HU} / \mathrm{ml}$ (table). However, no effect was noted with 25000 or $10000 \mathrm{HU} / \mathrm{ml}$. After exposure for $1-1.5 \mathrm{~h}$ to $50000 \mathrm{HU} / \mathrm{ml}$, cells were swollen and extruding from the upper third of the villi. After exposure for $0.5 \mathrm{~h}$, SEM showed that more cells were being shed from the extrusion zone of some villi than in control tissue. 
Table. Epithelial damage produced by $T$. hyodysenteriae haemolysin in intestinal loops of germfree pigs, as assessed by light microscopy and scanning electronmicroscopy

\begin{tabular}{|c|c|c|c|c|c|c|c|c|}
\hline \multirow[b]{4}{*}{$\begin{array}{l}\text { Pig } \\
\text { no. }\end{array}$} & \multicolumn{8}{|c|}{ Epithelial damage in } \\
\hline & \multicolumn{7}{|c|}{$\begin{array}{l}\text { ileum, treated with haemolysin } \\
\text { containing }\left(\mathrm{HU}, 10^{3} / \mathrm{ml}\right)\end{array}$} & $\begin{array}{c}\text { colon, treated } \\
\text { with haemolysin } \\
\text { containing } \\
\left(\mathrm{HU}, 10^{3} / \mathrm{ml}\right)\end{array}$ \\
\hline & \multirow[b]{2}{*}{$\begin{array}{c}100, \text { for } \\
3 \mathrm{~h}\end{array}$} & \multicolumn{4}{|c|}{50, for } & \multirow[b]{2}{*}{$\begin{array}{l}25, \text { for } \\
3 \mathrm{~h}\end{array}$} & \multirow[b]{2}{*}{$\begin{array}{l}10, \text { for } \\
3 \mathrm{~h}\end{array}$} & \multirow[b]{2}{*}{100, for $3 \mathrm{~h}$} \\
\hline & & $3 \mathrm{~h}$ & $1.5 \mathrm{~h}$ & $1 \mathrm{~h}$ & $0.5 \mathrm{~h}$ & & & \\
\hline 1 & +++ & ++ & $\mathbf{N}$ & + & $\mathbf{N}$ & $\mathbf{N}$ & $\mathbf{N}$ & - \\
\hline 3 & +++ & - & $\mathbf{N}$ & ++ & - & - & - & - \\
\hline 4 & +++ & + to +++ & $\mathbf{N}$ & $\mathbf{N}$ & $\mathbf{N}$ & - & - & - \\
\hline 5 & - & - & $\mathbf{N}$ & - & - & - & - & - \\
\hline 6 & ++++ & ++++ & $\mathbf{N}$ & +++ & + & - & - & - \\
\hline 7 & ++++ & +++ & $\mathbf{N}$ & ++ & + & - & - & ++++ \\
\hline 8 & $\mathbf{N}$ & ++ & ++ & + & + & $\mathbf{N}$ & $\mathbf{N}$ & ++++ \\
\hline 9 & ++++ & ++ & ++ & + & $\mathbf{N}$ & $\mathbf{N}$ & $\mathbf{N}$ & ++++ (patchy) \\
\hline
\end{tabular}

$\mathrm{N}$, Not done.

++++ , Villi almost obliterated in ileum, and flattened cells present in intercrypt area of colon; large accumulations of desquamated cells on surface of both ileum and colon.

+++ , Villi shortened, and sheets of epithelial cells lost into lumen.

++ , Area of extruded cells extending down from villus tip; pale staining cytoplasm; some shortening of villi.

+ , Enlarged extrusion zone, some cells obviously being extruded.

- , No effect.

The earliest change seen in the enterocytes by LM was pale staining cytoplasm. On TEM, the mitochondria were condensed and the endoplasmic reticulum was dilated; however the nuclei were swollen and the

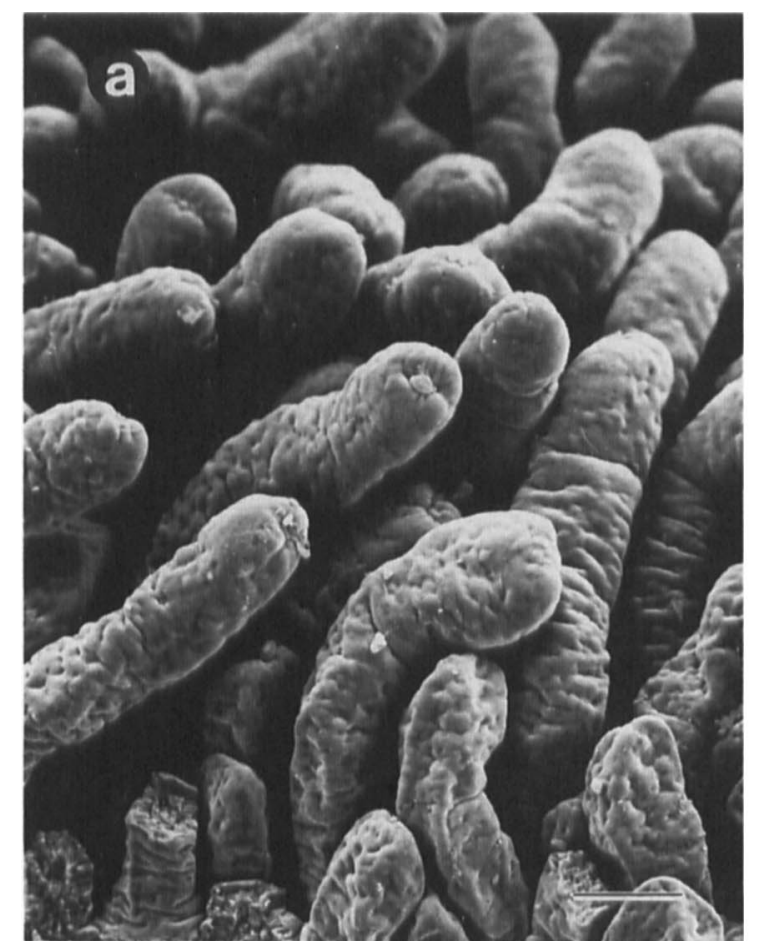

chromatin was dispersed; the microvillus border was intact with a clearly defined terminal web (fig. 2a). Enterocytes appeared normal in all the control loops when examined by LM and TEM (fig. 2b).
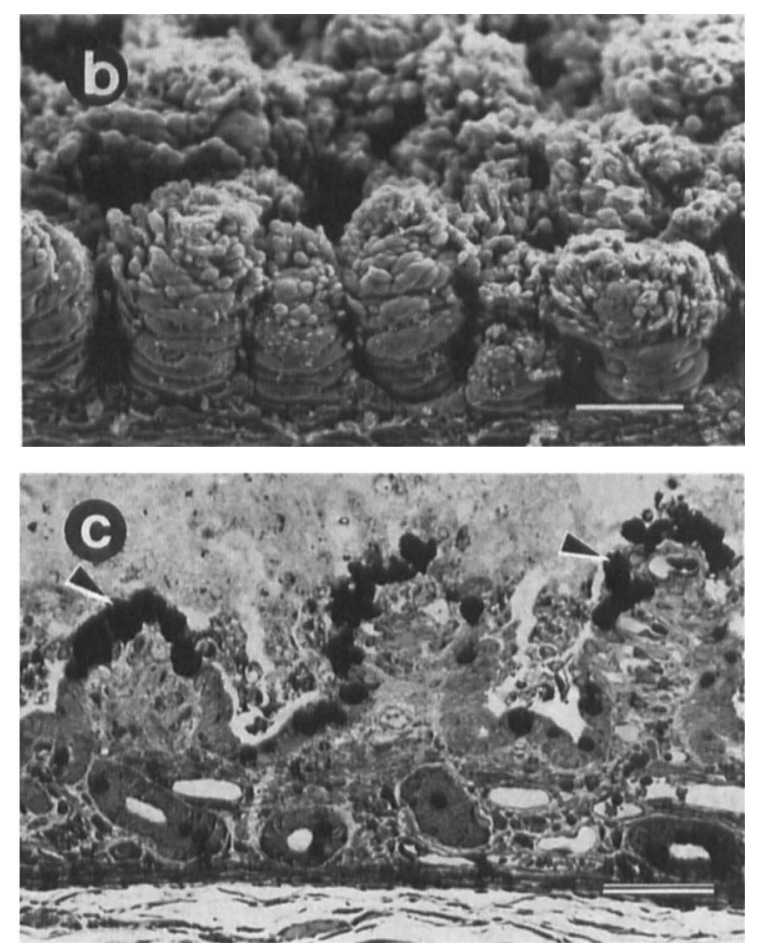

Fig. 1. Tissue from ileal loop of pig no. 6, which had been exposed for $3 \mathrm{~h}$ to haemolysin $100000 \mathrm{HU} / \mathrm{ml}$. (a) The haemolytic activity had been inactivated by heating to $56^{\circ} \mathrm{C}$ for $1 \mathrm{~h}$. SEM shows that there was no cytotoxic effect, the long, finger-like villi being undamaged (bar $=100 \mu \mathrm{m}$ ). (b) SEM of the mucosal surface of a loop inoculated with unheated haemolysin. The villi are severely stunted, with large numbers of exfoliated cells obscuring the surface (bar $=100 \mu \mathrm{m}$ ). (c) LM of a toluidine blue-stained section from the loop shown in $\mathrm{b}$. An accumulation of darkly staining goblet cells (indicated by arrows) covers the stunted villi (bar $=50 \mu \mathrm{m}$ ). 

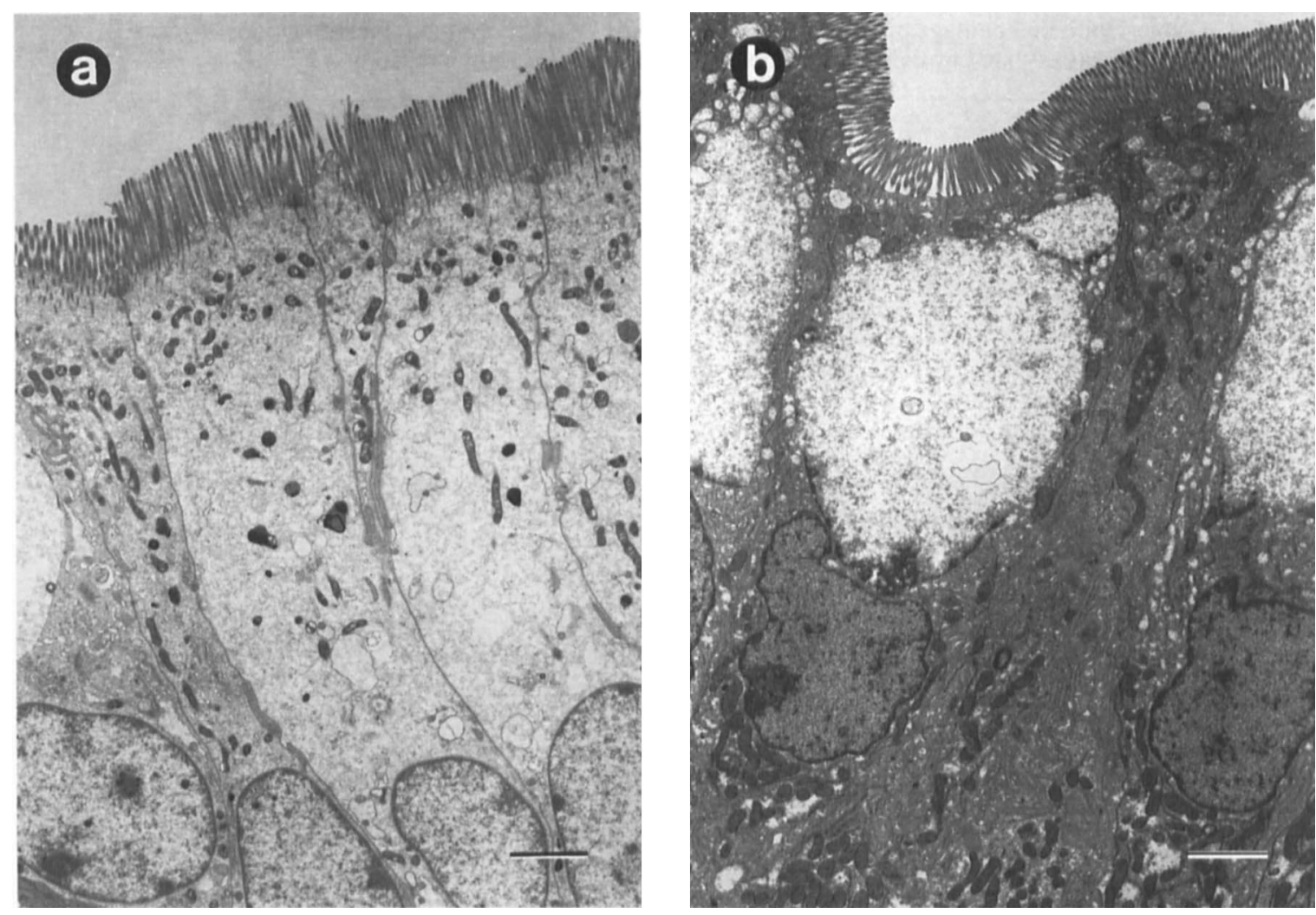

Fig. 2. TEM of epithelial cells from ileal loops of pig no. 6. (a) A loop exposed to haemolysin $50000 \mathrm{HU} / \mathrm{ml}$. After exposure for $1 \mathrm{~h}$, the mitochondria are condensed, the endoplasmic reticulum is dilated and the nuclei are swollen (bar $=2 \mu \mathrm{m})$. (b) A control loop containing a $0.5 \%$ RNA solution. After exposure for $3 \mathrm{~h}$ there are no signs of damage. Characteristic enterocytes contain regularly arranged organelles and large supranuclear vacuoles (bar $=2 \mu \mathrm{m})$.

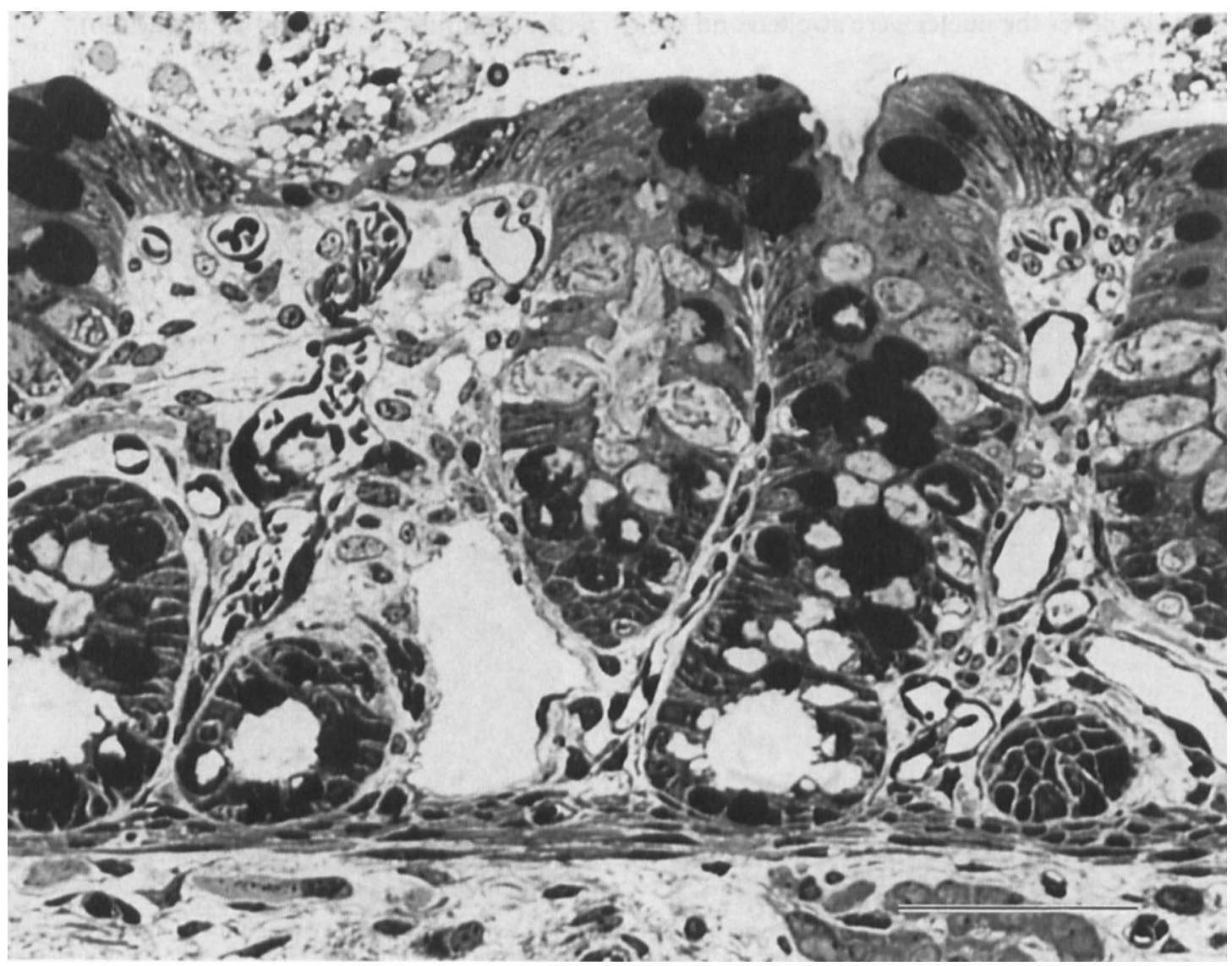

Fig. 3. The colonic mucosa from ligated loops of germ-free pig no. 7; a resin section stained with toluidine blue. The loop was exposed to haemolysin $100000 \mathrm{HU} / \mathrm{ml}$ from a virulent $T$. hyodysenteriae strain P18A for $3 \mathrm{~h}$. Note the exfoliation of epithelial cells in the intercrypt area. There is no accumulation of inflammatory cells $(\mathrm{bar}=50 \mu \mathrm{m})$ 

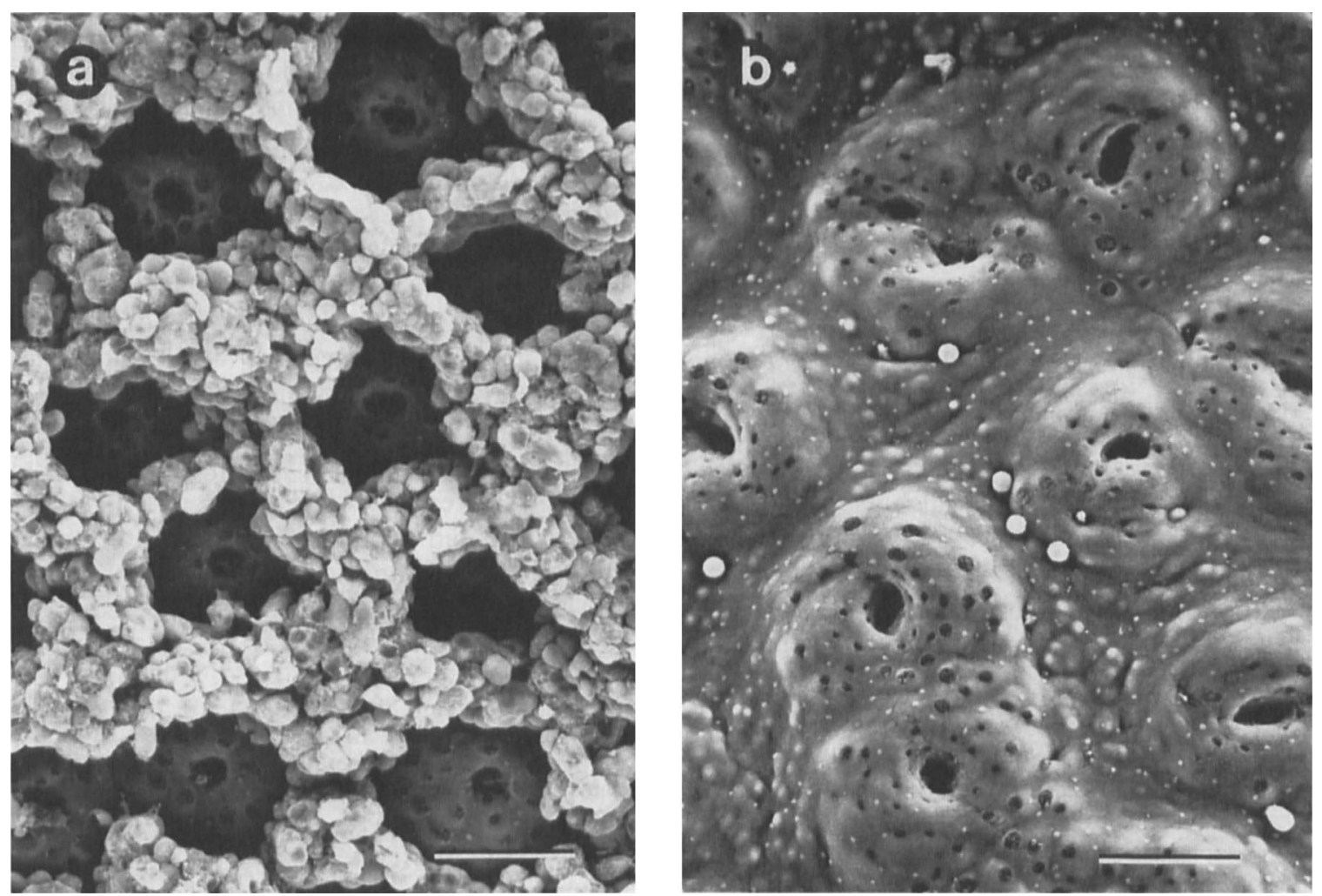

Fig. 4. SEM of the mucosal surface of colonic loops from pig no. 7. (a) After exposure for $3 \mathrm{~h}$ to haemolysin $100000 \mathrm{HU} / \mathrm{ml}$ a large number of cells are being extruded from the intercrypt area. Other cells appear to be unaffected (bar $=50 \mu \mathrm{m}$ ). (b) This ligated loop was exposed for $3 \mathrm{~h}$ to a $1 \%$ RNA solution. SEM shows no damage to the epithelial cells (bar $=50 \mu \mathrm{m})$.

\section{Effects on the colon}

Inocula containing haemolysin $100000 \mathrm{HU} / \mathrm{ml}$ gave inconsistent results in colonic loops: there was either severe damage (three pigs) or, when an appreciable amount of gut contents was present, no effect (five pigs). In pig 9 the effects were patchy, areas of severe damage being interspersed with areas of normal tissue. In damaged loops many enterocytes were sloughed from the intercrypt areas (figs. 3, 4a), leaving the cells of the crypt and its surrounds intact (fig. 4a). The remaining epithelial cells of the intercrypt area were flattened (fig. 3). There was some interstitial oedema in the lamina propria in some sections, but no accumulation of inflammatory cells (fig. 3). Above the surface was a mass of cell debris, which on SEM resembled a pseudomembrane (fig. 4a) and contrasted with tissue from control loops (fig. 4b).

\section{Discussion}

The results demonstrate the cytotoxic effects of the haemolysin from the virulent strain P18A on pig enterocytes in vivo. They differed from those in a study with rat ileal loops, ${ }^{12}$ in which fluid accumulation, haemorrhage, erosions of the epithelium and an inflammatory response were reported. None of these changes was seen in this study.

It is possible that the haemolysin preparation used contained treponemal LPS possessing endotoxin-like activity $^{3}$ and cytotoxicity. This seems unlikely, however, because the endotoxin would have caused an inflammatory response- which was not seen - and its effects would not have been inactivated by heating at $56^{\circ} \mathrm{C}$ for $1 \mathrm{~h}$.

A generally consistent dose response occurred (table). At $50000 \mathrm{HU} / \mathrm{ml}$, enterocyte damage was unequivocal by $1 \mathrm{~h}$ and severe by $3 \mathrm{~h}$. Cells apparently varied in their susceptibility to the toxin; goblet cells remained intact and accumulated as the enterocytes were lost. In the ileum, the mature enterocytes at the tips of the villi were affected first, damage occurring lower down the villi as the toxin concentration and time of exposure increased. The less differentiated cells of the crypts were unaffected. These findings may have been influenced by uneven diffusion of the toxin from the lumen into the folded layer of enterocytes, and by the inaccessibility of the crypt cells to the toxin. In the colon, however, there was a clear difference in susceptibility of the surface epithelial cells. Cells in the crypts and on the mucosal surface surrounding the crypt openings were unaffected while the epithelial enterocytes further from the crypt orifices, along the lines of exfoliation, were severely damaged and many appeared to be sloughing.

Because haemolysin is labile, ${ }^{4}$ and in ligated loops it must diffuse through the mucous layer to reach the enterocytes, a high concentration may be required. Also, haemolysin is inactivated by both ileal and 
colonic contents of germ-free pigs (Lysons, unpublished observations). Dilution or inactivation of toxin by intestinal contents may decrease the effective dose injected to a point below a threshold concentration of about $25000 \mathrm{HU} / \mathrm{ml}$. These factors may explain the variation in response between loops to the toxin. The presence of intestinal contents could have resulted in the failure of the haemolysin to cause any effect in pig 5 and the patchy damage in the colon of pig 9.

The mechanism by which the toxin affects the cells was not determined from these studies. Because exposure to haemolysin for as little as $0.5 \mathrm{~h}$ produced cytotoxic changes, the effect was probably direct and did not depend on mechanisms such as inhibition of protein synthesis. However, cytotoxicity appeared not to be a cell membrane lytic effect: the earliest changes were disruption of the internal cytoplasmic organelles, followed by swelling and finally shedding of epithelial cells.

The ligated loop serves as a means of studying the in-vivo action of haemolysin. In the natural disease there is extensive damage to the colonic mucosa with

\section{References}

1. Harris DL, Glock RD. Swine dysentery and spirochaetal diseases. In: Leman AD et al. (eds) Diseases of swine, 6th edn. Ames, Iowa State University Press. 1986: 494-507.

2. Glock RD, Harris DL. Swine dysentery. II Characterization of lesions in pigs inoculated with Treponema hyodysenteriae in pure and mixed culture. Vet Med Small Anim Clin 1972; 67: $65-68$.

3. Nuessen ME, Joens LA, Glock RD. Involvement of lipopolysaccharide in the pathogenicity of Treponema hyodysenteriae. J Immunol 1983; 131 : 997-999.

4. Kent KA. Haemolytic and adhesive properties of Treponema hyodysenteriae. Ph.D. Thesis, University of Reading, 1984.

5. Kent KA, Lemcke RM, Lysons RJ. Production, purification and molecular weight determination of the haemolysin of Treponema hyodysenteriae. J Med Microbiol. 1988; 27: 215224.

6. Loridan C, Alouf JE. Purification of RNA-core induced streptolysin $\mathrm{S}$, and isolation and haemolytic characteristics of the carrier-free toxin. J Gen Microbiol 1986; 132: 307315.

7. Lemcke RM, Burrows MR. Studies on a haemolysin produced by Treponema hyodysenteriae. J Med Microbiol 1982; 15: 205-214. sloughing of enterocytes. ${ }^{2,13} T$. hyodysenteriae colonises the mucous layer ${ }^{14}$ and from this position close to the epithelial cells it produces the cytotoxic haemolysin. The haemolysin, therefore, is less exposed to intestinal contents in the natural disease than in the ligated loop. It has been shown that $1 \mathrm{ml}$ of a broth culture $\left(6 \times 10^{8}\right.$ cells) can contain $2470 \mathrm{HU} .^{5}$ The invivo production of haemolysin has not been investigated, but it is possible that sufficient toxin is produced to account for the enterocyte death and exfoliation seen in early lesions of swine dysentery.

It is concluded that the haemolysin of the virulent strain P18A is a potent cytotoxin and a probable virulence determinant in swine dysentery. Use of ligated ileal and colonic loops in germ-free pigs should facilitate studies on the mode of action of the toxin and on the pathogenesis of swine dysentery.

We are grateful to Miss R. Hill, Mrs H. Prentice and Mrs H. Cook for technical assistance, to Mr D. Hawkins and Mr J. Quillam for processing the photographs and to Mrs R. Day for typing the manuscipt.

8. Taylor DJ, Alexander TJL. The production of dysentery in swine by feeding cultures containing a spirochaete. Brit Vet $J 1971$; 127: lviii-lxi.

9. Tavernor WD, Trexler PC, Vaughan LC, Cox JE, Jones DGC. The production of gnotobiotic piglets and calves by hysterotomy under general anaesthesia. Vet Rec $1971 ; 88$ : 10-14.

10. Whipp SC, Harris DL, Kinyon JM, Songer JG, Glock RD. Enteropathogenicity testing of Treponema hyodysenteriae in ligated colonic loops of swine. Am J Vet Res 1978; 39: 1293-1296.

11. Malick LE, Wilson RB. Modified thiocarbohydrazide procedure for scanning electron microscopy: routine use for normal, pathological, or experimental tissues. Stain Technol 1975; 50: 265-269.

12. Saheb SA, Lallier R, Massicotte L, Lafleur L, Lemieux S. Biological activity of Treponema hyodysenteriae hemolysin. Curr Microbiol 1981 ; 5: 91-94.

13. Blackmore WF, Taylor DJ. An agent possibly associated with swine dysentery. Vet Rec 1970; 87: 59-60.

14. Glock RD, Harris DL, Kluge JP. Localization of spirochetes with the structural characteristics of Treponema hyodysenteriae in the lesions of swine dysentery. Infect Immun 1974; 9: $167-178$. 